\section{Habitar un cuerpo. \\ Diseñar experiencias \\ emersivas en la época de los \\ espejismos digitales \\ Vanesa Melina D'Ortenzio ${ }^{(1)}$}

Resumen: En un mundo inmerso en la virtualidad, extasiado de imágenes y estímulos visuales, tanto la percepción de la otredad como la propia identidad tiende a sufrir alteraciones para adaptarse al medio. El surgimiento de espacios de encuentro virtuales, como blogs, foros y redes sociales, consolidó la masificación de una figura sumamente seductora e impensada hasta el momento: el avatar digital; la posibilidad de adoptar, personalizar, o moldear la propia identidad virtual y, con ella, nuevas formas de entender los vínculos. Frente a estas dos realidades (virtual e inmaterial) el sujeto parecería encontrarse escindido, en permanente conflicto entre su imagen proyectada y autopercibida. La pregunta que surge entonces y pone en marcha este artículo es la siguiente: ¿hasta qué punto la representación icónica, el sustituto digital, determina la forma en la que los individuos se perciben a sí mismos y se vinculan con otros? Finalmente, a partir de las herramientas aportadas por el Diseño de Transición, apelando a nociones de la arqueología de la imagen y la filosofía como sustento teórico y marco referencial, este trabajo se propone indagar sobre el nivel de impacto que tienen las experiencias inmersivas y emersivas en la construcción identitaria y vincular de los individuos, como punto de partida para pensar, desde el diseño, entornos virtuales más amigables, disminuyendo los impactos negativos y potenciando sus aportes positivos.

Palabras clave: Juego - Imagen - Identidad - Inmersión - Diseño - Interacción - Inclusión - Emersión - Experiencia de usuario - Sociedad - Virtualidad.

[Resúmenes en inglés y portugués en las páginas 258-259]

(1) Vanesa Melina D’Ortenzio es Licenciada en Diseño Gráfico por la Universidad de Palermo (UP), con el reconocimiento Mejor Proyecto de Graduación, categoría Investigación (Junio 2019). Orientada hacia el Diseño Social, consciente y sostenible, ha integrado la Comisión Diseño en Perspectiva en el IV Coloquio de Investigación y Desarrollo en Diseño Latino (Julio 2019) y en el V Coloquio Virtual Internacional de Investigadores en Diseño (Julio 2020). Su artículo Hiperconectados. La señalética y su impacto en los consensos sociales, fue publicado en esta línea de cuadernos. A su vez, se desempeña como Asistente Académica en la materia Diseño IV, Maestría en Gestión del Diseño (UP), dictada por la Doctoranda Daniela Di Bella. vanesa.dortenzio@gmail.com 


\section{Introducción}

El ser humano ha experimentado siempre cierta atracción por las imágenes; las diseña, materializa y les asigna valor, sin comprender cabalmente el impacto que estas tienen en el modo en que se percibe a sí mismo, a su entorno y a aquellos que lo rodean. Hans Belting, historiador del arte e investigador de las teorías de la imagen, afirma que desde la perspectiva antropológica el ser humano no es considerado "amo de imágenes, sino algo completamente distinto- como lugar de imágenes que toman posesión de su cuerpo: está a merced de las imágenes auto engendradas, aún cuando siempre intente dominarlas" (Belting, 2007, p. 14). Atendiendo a estas consideraciones, la transición hacia una sociedad más sostenible requiere una visión sistémica, que incorpore nuevas formas de pensar y abordar la actividad del diseñador, en tanto productor de imágenes y, por tanto, universos de sentido. Por su parte, resulta imprescindible que aquello que se visione se encuentre guiado por un profundo entendimiento de los cambios y las dinámicas actuales (Irwin, 2019); es en este punto que el Diseño de Transición ingresa como marco referencial indispensable a la hora de abordar toda problemática vinculada a la comunicación y la producción de sentido en la actualidad. Siguiendo esta línea, el presente trabajo indagará sobre el vínculo entre sujeto-objeto sustituto o avatar, entendiendo a este último como representación icónica del sujeto en el mundo virtual.

Para abordar esta problemática, como se mencionó anteriormente, se recurre al Diseño de Transición, en tanto "lente para el análisis, y como herramienta para recontextualizar el presente y el futuro" (Vinlove, 2020/2021). El conjunto de herramientas aportadas por el Diseño de Transición permite analizar la complejidad que rodea a los juegos electrónicos en su carácter de híbridos culturales (Huhtamo, 2007), cambiantes y dinámicos, que dan cuenta tanto de la tendencia hacia la inmersión propia de los individuos como de su búsqueda permanente de presentación. En este sentido, el doctor Samuel Gallastegui, docente e investigador de las artes interactivas, sostiene que en la actualidad "ya no se produce solamente una inmersión en los juegos digitales, sino que el contenido del juego y la experiencia de la persona trascienden más allá de sus fronteras, emergiendo a la vida y al espacio cotidiano" (Gallastegui, 2018, p. 52). Este fenómeno actual caracterizado por la emergencia de lo virtual dentro de la realidad concreta es lo que puso en marcha la presente investigación.

Abordar este tema implica, necesariamente, indagar sobre el carácter simbólico que se le otorga a las imágenes. Al respecto, Belting (2007) releva el tratamiento que se ha realizado de la imagen en el plano de la filosofía, destacando la noción de crisis de representación en la sociedad moderna, a partir de la cual se responsabilizó a las imágenes de que el mundo haya entrado en crisis. Siguiendo esta línea, Jean Baudrillard denomina a las imágenes asesinas de lo real; "Lo real se transforma así en una certeza ontológica, a la que las imágenes tienen que, y deben, renunciar” (Belting, 2007, p. 23). En palabras de Belting:

La crisis de la representación es en realidad una duda en cuanto a la referencia, que hemos dejado de confiar en las imágenes. Las imágenes fracasan únicamente cuando ya no encontramos en ellas ninguna analogía con aquello que las precede y con lo que se las puede relacionar en el mundo... Para Baudri- 
llard, toda imagen en la que no se pueda leer alguna prueba de realidad equivale a un simulacro, así como sospecha que existe una simulación donde no se respeta la equivalencia por él propuesta entre signo y significado (Belting, 2007, p. 23).

Esta relación entre objeto y copia sustituta o representación icónica, será abordada para analizar la noción de avatar y su vinculación con los elementos sintéticos constitutivos de las experiencias inmersivas. Esta indagación requiere, a su vez, un análisis sobre la naturaleza del diseño, sus límites y alcances en relación al impacto social que tiene la intervención del diseño en la aparición, implementación y masificación de ciertos productos culturales. Al respecto, Terry Irwin afirma que el diseño de transición "reconoce y da por aceptada la noción de que vivimos en tiempos de transición y toma como premisa central la gestación de transiciones sociales hacia un futuro más sostenible". En este escenario, los diseñadores son llamados a adoptar un rol activo en tanto agentes de cambio, involucrados en la planificación y desarrollo de políticas destinadas a dar soluciones a los problemas de la sociedad actual (Irwin en Di Bella, 2020, p. 176).

Este marco de análisis, a su vez, invita a abordar las problemáticas desde una perspectiva heurística. "La transición hacia futuros sostenibles es un proceso de diseño que requiere una visión, la integración del conocimiento y la necesidad de pensar y actuar en diferentes niveles de escala, y que también es altamente contextual” (Kossoff, 2011, pp. 5-24). Siguiendo esta línea, con el objetivo de comprender la profundidad y alcance del caso estudiado, este trabajo se detiene en cuatro temas-eje: la importancia social y cultural del juego; las escalas y niveles de inmersión en los entornos digitales; los principales impactos -positivos y negativos- de la interacción sujeto/videojuego y, finalmente, las propuestas para disminuir los impactos negativos de las experiencias lúdicas inmersivas.

\section{Definición y aproximaciones}

\section{El círculo mágico y la suspensión de la incredulidad}

Johan Huizinga, profesor, historiador e investigador, analiza en su libro Homo ludens (Huizinga, 2007) la importancia del juego dentro de la cultura y destaca el acto de jugar como algo inherente a la cultura humana. A su vez, afirma que el juego se origina y sustenta en un acto de poiesis: materializa espacios y objetos antes reservados al imaginario o al inconsciente de los individuos, a partir de la reproducción y representación de figuras alegóricas.

Por su parte, el jugador, inmerso en la experiencia lúdica, debe asignarle valor personal a los objetos y al medio con el que interactúa. Para que el desarrollo de la experiencia sea posible, debe creer que está jugando y aceptar las reglas que el universo ficcional le propone. Si los principios del jugador resultan incompatibles con los del juego y, por consiguiente, con los del resto de los jugadores que aceptaron las normas del juego, este se rompe o la 
persona de comportamiento disonante queda aislada del resto. Es decir, el acto de jugar, además de poseer una motivación emocional, implica cierto grado de cultura y aprendizaje por parte de los jugadores, que se manifiesta en el consenso y aceptación de aquellas normas que hacen a la interacción posible. El jugador no sólo acepta sino que internaliza estas reglas y las ejerce a partir de un proceso de personificación (Huizinga, 2007).

Siguiendo esta línea, Huizinga (2007) desarrolla el concepto de Círculo Mágico, definiéndolo como el espacio, ideal o material, donde el juego ocurre; es decir, el área que delimita -de forma real o simbólica- el juego y lo separa del mundo real, con el objeto de proteger la integridad de este último. En palabras de Gallastegui:

Más allá de la mera separación entre lo físico y lo virtual, el círculo mágico es la propia interfaz de los acontecimientos lúdicos, la piel del juego; es esa superficie que contiene al juego, pero también el código que permite que el jugador pueda participar en él, el nexo de unión entre el juego y la vida (Gallastegui, 2018, p. 54).

Dentro del círculo mágico se disuelven ciertas pautas socialmente instituidas y acciones consideradas inadecuadas o ilegales -como actos violentos, asesinatos y traiciones- están permitidas y son necesarias para el desarrollo del juego. Esta demarcación de los límites y alcances del juego es únicamente posible a partir del proceso de personificación antes mencionado: el círculo mágico es un consenso más, el acuerdo que delimita los límites y alcances del juego. Al respecto, Gallastegui afirma que:

La inmersión lúdica... es la experiencia de introducirse en un ámbito diferenciado de la realidad ordinaria, con sus propias reglas, contenido en sí mismo, y que mantiene la separación entre lo que es juego y lo que es vida. Tradicionalmente se ha utilizado el término 'círculo mágico', que es útil para denotar el estado de excepción que comienza con el juego, estructurado por normas que los participantes negocian y aceptan (Gallastegui, 2018, p. 54).

El círculo mágico se rompe únicamente cuando algún individuo transgrede de manera intencional alguna regla. En este punto cabe aclarar que el círculo mágico, si bien protege a la realidad del universo ficcional, no aísla completamente ambos mundos: el jugador trae consigo un bagaje de saberes y valores que van a incidir indefectiblemente en su comportamiento. Al respecto, "la cultura del diseño establece representaciones normalizantes, es decir, formas aceptadas de percibirse como individuo y en el entorno" (D'Ortenzio, 2020/2021, p. 134), estos modos de ser y actuar designados por la cultura inciden de forma determinante en cómo el individuo se comportará dentro del mundo virtual.

Por su parte, la suspensión de la incredulidad es un término que suele confundirse con la noción de Círculo mágico pero que, si bien están asociados -sin el primero no hay margen de posibilidad para el segundo- no representan lo mismo. La suspensión de la incredulidad es otro pacto tácito entre el jugador y el juego, indispensable para el desarrollo del mismo. Hace referencia a la voluntad del individuo para aceptar el universo ficcional que se le presenta ante sus ojos, independientemente de que este sea verosímil o no. Mediante 
esta acción, el sujeto suspende su sentido crítico para adentrarse en la narrativa propuesta (Huizinga, 2007). Debido a que los videojuegos son experiencias marcadamente inmersivas -y en algunos casos, como se explicará más adelante, con un fuerte componente emersivo- la suspensión de la incredulidad es clave; ignorar las inconsistencias y errores del juego permiten al usuario una experiencia más vívida del mundo ficcional en el que está inmerso.

La suspensión de la incredulidad, lejos de circunscribirse únicamente al ámbito de los videojuegos, es esencial a todo tipo de contemplación estética y por tanto puede observarse ante cualquier producto cultural, sea una obra de arte, una película, un show de ilusionismo, etc.

\section{El impulso hacia la inmersión y la avatización de la mirada}

"Baudrillard nos hace caer en cuenta de que la seducción opera sistemáticamente en la forma de una metafísica radical del fingimiento" (Tillería Aqueveque 2019, p. 13). Atendiendo a este enunciado, el hombre parecería estar inclinado a dejarse seducir por la ficción. La numerosa cantidad de actividades y dispositivos lúdicos producidos a lo largo de la historia dan cuenta de la atracción y fascinación que ejercen los juegos y las experiencias inmersivas en los seres humanos. Estas actividades pueden rastrearse hasta los orígenes de la humanidad, a las pinturas rupestres, no sólo por su carácter representativo sino por su presunto valor simbólico: más que imágenes, se consideran experiencias, parte de un todo interactivo que, fusionado con la iluminación y ambientación adecuada, formaban parte de rituales prehistóricos. Estos mundos ficcionales, materializados a través de la imagen, poseen a lo largo de la historia un hilo conductor: la necesidad manifiesta de representación; la búsqueda permanente de dejar una huella que de cuenta del paso de la humanidad por el mundo. Siguiendo esta línea, Andrea Pinotti, profesor de estética e investigador de la imagen, define este fenómeno de la siguiente manera:

$\mathrm{Al}$ igual que el impulso de inmersión, que se remonta a la dimensión ahistórica del mito, el estado avatar en el sentido más amplio del término -es decir, como la presencia sustitutiva del productor o usuario de la imagen- también puede ser identificado como una estrategia que ha estado en funcionamiento desde la antigüedad (Pinotti, 2020).

En esta búsqueda de representación los avatares desempeñan un papel fundamental dentro de la dinámica inmersiva que caracteriza a la sociedad contemporánea: constituyen la representación gráfica identitaria a partir de la cual los individuos "negocian su presencia e interactúan con objetos sintéticos u otros avatares del mundo digital” (Pinotti, 2020). El avatar es, entonces, condición necesaria para habitar y diferenciarse dentro los universos virtuales. Asimismo, "el espectro funcional del avatar va desde la revelación del Sí mismo (una especie de autorretrato veraz) hasta el ocultamiento de la máscara” (Pinotti, 2020), es decir, actúa como un sustituto del individuo que remite pero no se limita a este; en su lugar, habilita una infinita cantidad de posibilidades y negociaciones a partir de los cuales el sujeto puede elegir representarse tal cual es (en el mundo real) o adoptar características diametralmente opuestas. Es por este motivo que a partir de la avatarización los individuos pueden llegar a experimentar el fenómeno peculiar de la autoempatía: "la posibili- 
dad de empatizar con el otro en mí, de asumir la perspectiva del mundo desde un punto de vista ajeno al mío, pero siempre de alguna manera propio" (Pinotti, 2020).

Para comprender el alcance del término, es preciso comprender su origen. La noción de avatar comenzó a utilizarse en idiomas occidentales a partir del S XVIII pero posee raíces más antiguas: se desprende del término sánscrito avatāra y está vinculado a una antigua creencia hindú que alude al descenso de una deidad a la tierra. Según la creencia, esta deidad asume una forma para hacerse visible pero aquello que se ve, lo manifiesto, es sólo una representación parcial de la divinidad (Pinotti, 2020). Atendiendo a estas consideraciones, se podría afirmar que el origen del término da cuenta de la propiedad única e inigualable del avatar: habilita instancias de visibilidad y ocultamiento de acuerdo a las necesidades del sujeto.

Es posible trazar un paralelismo entre los mencionados proto-avatares prehistóricos y los avatares virtuales de la sociedad contemporánea: ambos encarnan representaciones icónicas que dan cuenta de una identidad determinada y existen sólo a partir y en relación a aquello representado. En otras palabras, los avatares necesitan el reflejo de la realidad, su duplicación, al tiempo que posibilitan "tanto el autoreconocimiento como la autoduplicación" (Pinotti, 2020). Asimismo, en relación con el tema planteado, se encuentran en el universo icónico diversos adminículos que complementan el estatus y terminan de configurar la identidad-otra del individuo:

El orden visual (entre otros actores) intervino de manera histórica, y en la manera en que el sujeto de la modernidad ha conocido y representado su propio cuerpo. Ha determinado los modos de tipificar los cuerpos de las personas y de interpretar lo social. A través de la dimensión corporal se ejerce la regulación y el control social de los sujetos, la sociología ha interpretado las prácticas del vestir y en especial en el universo de la moda, como hechos sociales que ponen en evidencia la construcción cultural de la conformación social de los cuerpo (Vinlove, 2020/2021, p. 150).

Por su parte, el vínculo del sujeto con su representación se remonta a la era pre virtual; en el terreno de las bellas artes, encuentra su máxima expresión en el autorretrato, donde la asociación del objeto representado con su sustituto pictórico estaba dada por una relación de diálogo y semejanza: "el yo fuera de la imagen debe dirigirse al otro yo dentro de la imagen en una relación $I$-Tu para producir un auto-reconocimiento como un espejo" (Pinotti, 2020). En otras palabras, la representación, la copia, actúa como reflejo de lo real; se parece, remite a aquello que representa. Hay una retroalimentación entre la representación y el sujeto/objeto representado basado en una relación de similitud y diferencia. Siguiendo esta línea, Baudrillard analiza el caso paradigmático del trompe-l'oeil.

En el trompe-l'oeil [más falso que lo falso] no se trata de confundirse con lo real, se trata de producir un simulacro con plena consciencia del juego y del artificio (Baudrillard, 2000, p. 64). Los objetos del trompe-l'oeil (sin referencia, aislados, sacados de su marco) parodian la teatralidad de la vida, remedan la tercera dimensión, pero anacrónicamente, mediante un exceso de realidad. Por lo mis- 
mo, la seducción del trompe-l'oeil no es estética (el trompe-l'oeil ya no es pintura) sino metafísica: proviene de una sorpresa radical de las apariencias (Baudrillard, 2000, p. 65). La «hipersimulación experimental» del trompe-l’oeil no es arte sino alegoría, o lo que es igual, simulación pura (Tillería Aqueveque, 2019, p. 13).

A partir de lo analizado, resulta pertinente afirmar que la mirada cumple un rol determinante para cualquier experiencia lúdica inmersiva. Asimismo, al sumarle a la percepción audiovisual complementos y recursos multisensoriales y/o multimodales, la concepción misma sufre modificaciones para acercarse a la noción de experiencia: el sujeto, inmerso en el mundo virtual que se le presenta y dotado de diversos tipos de estímulos, ya no es un mero espectador sino que forma parte, interviene activamente (Pinotti, 2020). Desde la narrativa de los videojuegos hay múltiples recursos que construyen la mirada del jugador -por ejemplo, el encuadre subjetivo, el disparo en primera persona y el disparo en plena empatía- estos elementos hacen de las vivencias del avatar una "experiencia de la presencia inmersiva del Sí mismo" (Pinotti, 2020) dentro del entorno virtual que no requiere la presencia visible del avatar sino que está vinculada a "una declinación particular de la mirada, de la perspectiva del mundo experimentado como representante del Sí mismo" (Pinotti, 2020).

\section{El hombre y la máquina. Una mirada arqueológica del juego}

En su artículo “Máquinas de diversión, máquinas de problemas”, el profesor, investigador y arqueólogo de los medios Erkki Huhtamo indaga sobre la relación hombre-máquina, haciendo particular énfasis en el vínculo de los individuos con las máquinas de juego a lo largo de la historia. El autor afirma que "La industria cada vez muestra más signos de sustituir la palabra juegos por entretenimiento" (Huhtamo 2007, p. 1) a causa de la connotación históricamente negativa asociada al término jugar. Esta tendencia a diferenciar al juego de la actividad sería, lejos de ser algo inocente, responde a la estrategia que posibilitó la inserción de las máquinas de juego en el mercado de forma masiva a principios del siglo XX: presentadas como contra-máquinas, para diferenciarse de las máquinas de trabajo, se ofrecieron como medio de esparcimiento para los empleados y obreros; una válvula de escape a sus preocupaciones diarias. En palabras de Huhtamo:

La misma gente que pasaba sus días «encadenada» a las máquinas en fábricas y oficinas podía reunirse alrededor de estas diferentes máquinas durante sus descansos para comer o a la salida del trabajo o durante los fines de semana... Proporcionaban una vía de escape que no apartaba demasiado a los usuarios de sus obligaciones en la vida diaria (Huhtamo 2007, p. 11).

Las máquinas de juego estaban diseñadas para tener un efecto hipnótico y adictivo, sobre el usuario; tanto las mecánicas de juego como el entorno donde se emplazaba la máquina 
estaban pensados para tal fin. Por su parte, el resultado del juego dependía, en la mayoría de los casos, de la suerte y no de las capacidades o destrezas particulares del jugador. Estas máquinas de azar ofrecían oportunidades muy escasas de ganar algo, al tiempo que implican un alto grado de interacción. Este hecho constituía su principal elemento de captación de usuarios: "La repetición mecánica era para inducir a la repetición psicológica, que a veces se manifestaba como comportamiento compulsivo. El objetivo era hacer que el usuario gastara más y más monedas a un ritmo cada vez más elevado" (Huhtamo 2007, p. 9). En la actualidad, el paradigma de que los universos virtuales meramente inmersivos está perdiendo dominio frente al surgimiento de nuevas tecnologías y dinámicas de juego que invitan a redefinir los límites de lo real y lo virtual. "La computación ubicua, las tecnologías nómadas y los dispositivos geolocalizados están cambiando de forma trepidante la relación entre el espacio virtual y espacio físico, así como entre juego y vida" (Gallastegui, 2018 , p. 54). Siguiendo este razonamiento, los límites entre el espacio físico, real, y el virtual entran en crisis debido a una superposición entre ambos; producto de este cruce, se han fundido las fronteras que históricamente los diferenciaban. Por su parte, la tecnología está posibilitando formas hasta el momento impensadas de retroalimentación e interacción entre ambos mundos, lo que se traduce en una inevitable redefinición del vínculo entre los jugadores y el juego que "ya no puede ser descrita sólo en términos de inmersión, entendida como metáfora que describe la experiencia de sumergirse en un espacio virtual o en un mundo ficcional" (Gallastegui, 2018, p. 53). Esta irrupción de lo virtual en el terreno real trajo consigo una serie de efectos en la conducta, autopercepción y formas de interacción de los individuos, fenómeno que se analizará en los siguientes apartados.

\section{Aplicaciones. Tipos de inmersión y escalas de interacción}

En la actualidad, los videojuegos comprenden un amplio espectro de actividades y aplicaciones, a menudo vinculadas a la educación, capacitación, venta de productos y servicios. Frente al implacable avance de las tecnologías inmersivas y emersivas -las cuales se analizarán en este apartado- "las fronteras físico-virtual y juego-vida, que en los modelos de juegos digitales previos estaban más diferenciadas, ahora se han difuminado y solapado (Gallastegui, 2018, p. 54). Esto conduce a "un nuevo tipo de percepción del juego digital como medio vital y espacial” (Gallastegui, 2018, p. 54), a partir del cual el juego emerge a la vida del usuario, quien ya no tiene la sensación de entrar o salir de este sino que, contrariamente, lo percibe como algo integrado a su vida cotidiana. En otras palabras, el hecho emersivo puede enunciarse de la siguiente manera:

El juego orienta su contenido desde el espacio virtual hacia el espacio físico, y desde el ámbito lúdico hacia el ámbito ordinario. Este fenómeno, que es común a las manifestaciones lúdicas que difuminan las fronteras juego-vida y virtual-físico, se puede identificar mediante el concepto de emersión (Gallastegui, 2018, p. 55). 
Resulta pertinente definir las nociones inmersión y emersión, en la medida que constituyen uno de los ejes estructuradores de este trabajo. Ambos términos pueden considerarse como partes opuestas del mismo fenómeno: mientras que en un extremo se ubican los juegos de naturaleza completamente inmersiva, en cuyo espacio de acción se sumerge el usuario para cumplir determinada misión, en el otro extremo se encuentran los juegos de orientación eminentemente emersiva, que invitan al jugador a interactuar con elementos sintéticos en el propio entorno real. Como ejemplos del primer orden se pueden mencionar los juegos de disparos en primera persona y en el caso del segundo, los juegos que se sirven de la geolocalización -es decir, de la ubicación del usuario- para que el desarrollo del juego sea posible (Gallastegui, 2018). Asimismo, entre ambos recursos existe un continuo de inmersividad-emersividad, a partir del cual se sitúan los diferentes tipos de experiencias inmersivas/emersivas, de acuerdo a la relación preponderante entre juego y jugador. $\mathrm{Al}$ respecto, "existe un continuo de posibilidades entre ambas posiciones extremas, que puede ser dividido en tres dimensiones: interacción, representación e interacción" (Gallastegui, 2018, p. 71). Dicha interacción se produce en la interfaz, entre el mundo lúdico ficcional y el espacio real del usuario. La misma pertenecer a los siguientes ámbitos:

A. La interfaz entre el usuario y la tecnología, que utiliza instrumentos y dispositivos de interacción inmersivos, como los cascos y trajes de datos, o emersivos, como en la interacción directa con el objeto. B. La interfaz entre el espacio físico y el virtual, que representa diferentes grados de virtualidad o realidad, que pueden ser inmersivos, como un mundo completamente virtual, o emersivos, como las imágenes de vídeo grabadas de la realidad, o incluso la combinación de ambos, como es el caso de la realidad aumentada. C. La interfaz entre el mundo de juego y el real, que se realiza mediante estrategias y modelos narrativos inmersivos, como un juego que crea una narración ficticia desconectada de la realidad, o emersivos, como uno que incluye hechos, motivaciones y objetivos reales en sus mecánicas (Gallastegui, 2018, p. 56).

Esta clasificación surgió a partir del análisis y comparación de numerosos y variados casos paradigmáticos. Por otra parte, el modelo de análisis propuesto Gallastegui (2018) determina que cada uno de estos ejes clasificatorios se divide, a su vez, en siete grados diferentes que indican su nivel de emersividad (Ver Tabla 1):

ESCALAS DE INTERACCIÓN, REPRESENTACIÓN Y NARRACIÓN

\begin{tabular}{|c|c|}
\hline \multirow[t]{4}{*}{ A) Escala de interacción } & 1. Dispositivos multimodales de realidad virtual \\
\hline & 2. Mandos simuladores \\
\hline & 3. Dispositivos generalistas. \\
\hline & 4. Reconocimiento de gestos. \\
\hline
\end{tabular}




\begin{tabular}{|l|l|}
\hline \multirow{5}{*}{ B) Escala de representación } & 5. Dispositivos geolocalizados. \\
\cline { 2 - 3 } & 6. Controladores remotos. \\
\hline 7. Interacción no-mediada. \\
\cline { 2 - 3 } & 1. Representación virtual. \\
\hline 2. Virtualidad aumentada. \\
\hline 3. Entorno de escritorio. \\
\cline { 2 - 3 } & 4. Realidad virtualizada. \\
\hline & 5. Ventana virtual. \\
\hline & 6. Realidad aumentada \\
\hline 7. Imágenes de la realidad \\
\hline C) Escala de narración & 1. Videojuego tradicional \\
\hline & 2. Metaverso \\
\hline 3. Juego ubicuo y pervasivo. \\
\hline 4. Juego de realidad alternativa \\
\hline 5. Juego serio. \\
\hline 6. Proceso ludificado \\
\hline 7. Juegos de realidad \\
\hline
\end{tabular}

Tabla 1. Clasificación de niveles de emersividad (Gallastegui, 2018). Fuente: elaboración propia.

A) Escala de interacción: esta clasificación gradúa la relación entre la persona y la computadora, según el grado de mediación presente entre ambos. Los dispositivos mediadores pueden dividirse en: dispositivos de entrada, tales como el teclado, mouse, gamepad o simuladores; dispositivos salida, que proporcionan estímulos visuales, auditivos o hápticos, como pueden ser las pantallas, parlantes o controles de mando vibradores y, finalmente, los dispositivos multimodales, que representan una gran mediación y alta capacidad inmersiva. Algunos ejemplos de este último grado serían los cascos y gafas de realidad virtual (Gallastegui, 2018). La escala, a su vez, comprende 7 grados (Ver Tabla 1) que contemplan un amplio espectro de dispositivos de realidad virtual, "ya sea envolventes, hápticos o montados en la cabeza, hasta la interacción directa con el espacio físico y la realidad ordinaria" (Gallastegui, 2018, p. 57). 
B) Escala de representación: se centra en la imagen, en su cualidad representativa. Esta clasificación gradúa la relación entre las imágenes, en función a si estas son creadas artificialmente o si, en cambio, dependen de la realidad concreta (Gallastegui, 2018). Las representaciones comprendidas en esta clasificación abarcan las imágenes de espacios completamente virtuales, las que remiten o se vinculan a espacios físicos concretos y "todas las hibridaciones posibles entre ambos casos diametralmente opuestos" (Gallastegui, 2018, p. 58), a partir de las cuales el autor diferencia siete casos intermedios (Ver Tabla 1).

C) Escala de narración: enfocada en el contenido del juego, gradúa la relación entre ficción y realidad a partir del análisis del contenido narrativo del mismo, es decir, la trama, el reto, la misión, que guía el desarrollo de los acontecimientos y moviliza la acción. Al respecto, "el factor clave es la acción, con sus potenciales motivaciones y repercusiones" (Gallastegui, 2018, p. 63). Si las motivaciones que ponen en marcha al juego pertenecen a la realidad concreta del individuo e inciden directamente en esta -por ejemplo, aprender a tocar algún instrumento-, el juego resultará eminentemente emersivo en la escala de la narración. "Si, por el contrario, las motivaciones y repercusiones de la acción vienen impuestas en la historia, el jugador se sumerge en la narración propuesta, tendiendo a la inmersión" (Gallastegui, 2018, p. 63). Dicha escala define y delimita siete grados entre los videojuegos y los juegos tradicionales que tienen lugar en la realidad cotidiana (Ver Tabla 1).

A partir de lo analizado resulta pertinente afirmar que los dispositivos de interacción, los modos de representación y los modelos narrativos articulan la acción del juego hacia el interior del propio entorno virtual o, por el contrario, desbordan hacia la realidad concreta del jugador. Asimismo, esta relación no es fija y puede sufrir alteraciones conforme se agreguen o quiten elementos al videojuego. Expresado de otra manera, la experiencia inmersiva puede alterarse para dotar al juego de un carácter más emersivo, en cualquiera de sus tres ejes (Gallastegui, 2018).

\section{De lo virtual a lo real. Principales impactos}

\section{Adoptar la mirada-otra. Estimulación de procesos empáticos:}

"Lejos de ser un acceso unívoco de lo real a lo digital, los avatares constituyen una mediación bidireccional, que también permite intervenciones desde el mundo virtual al real" (Pinotti, 2020). Como se mencionó anteriormente, la noción de avatar abre una cantidad virtualmente infinita de combinaciones a la hora de definir el aspecto y las características del sustituto digital. (Pinotti, 2020). Al respecto, Pinotti afirma que diversos estudios neurocognitivos han demostrado que el uso de avatares tiene un impacto en la vida real de los individuos, modificando la forma en la que estos perciben a la otredad, redefiniendo prejuicios de étnicos y de género, 
Mediante la producción de la llamada ilusión de propiedad de todo el cuerpo: adoptar un avatar de un género diferente (por ejemplo, en el caso de la violencia doméstica) o ponerse en un avatar con un color de piel diferente en el entorno virtual es una experiencia que puede reverberar en el mundo real, ayudando a corregir los estereotipos sociales mediante la adopción de una toma de perspectiva alternativa y la estimulación de procesos empáticos. Las representaciones corporales de nivel inferior condicionan las actitudes y creencias de nivel superior. Como lo formuló eficazmente un grupo de investigadores que trabajan intensamente en estas cuestiones, Cambiar los cuerpos cambia las mentes (Pinotti, 2020).

Asimismo, el uso de avatares ha demostrado ser particularmente significativo en el tratamiento clínico de síndromes patológicos, tales como la detección de Alteraciones de la imagen corporal BID, vinculados a diversos trastornos de alimentación o los síntomas característicos del Trastorno de estrés postraumático (Pinotti, 2020).

\section{La variable adictiva}

Por otra parte, en el año 2018 la OMS incorporó en su apartado web ICD-11 for Mortality and Morbidity Statistics -sección que aborda los desórdenes y trastornos asociados a comportamientos adictivos-, la adicción a los videojuegos como trastorno, definiendo a la misma como "una adicción persistente o repetida a los juegos online u offline" (Infobae, 2018). Entre los síntomas característicos, la OMS enumeró tres conductas: en primera instancia, la incapacidad de la persona para controlar la duración, frecuencia e intensidad del juego; en segundo nivel, el hecho observado que los juegos pasan a tener una notable preponderancia por sobre el resto de las actividades e intereses del individuo y, en tercera instancia, la persistencia: la conducta se mantiene a pesar de las consecuencias negativas en el individuo. En otras palabras, "el hecho de jugar a un videojuego no es nocivo por sí mismo, al igual que tampoco lo es ingerir alcohol, algo que hace regularmente el $40 \%$ de la población mundial, el problema existe cuando el consumo es abusivo y cambia el comportamiento de la persona que lo ejerce" (Schulkin, 2020). La OMS, por su parte, estima que entre un $2 \%$ y un $3 \%$ de las personas que juegan a videojuegos de forma frecuente tienen un comportamiento abusivo y pernicioso (Infobae, 2018). Por otra parte, un estudio alemán presentado en el marco del V Foro Europeo de Investigadores de Neurociencia reveló que los videojuegos actúan sobre el cerebro de la misma manera que otras sustancias adictivas, creando dependencia; conclusión a la que se arribó tras analizar los resultados de más de 7000 pruebas y descubrir que más del 10\% de las personas evaluadas "desarrollaba una memoria de adicción ante los videojuegos... Su cerebro asociaba los videojuegos a sensaciones positivas debido a la liberación de dopamina" (La Nación, 2018).

Asimismo, si bien la adicción a la tecnología y los videojuegos crece de modo exponencial, este fenómeno podría ser tan solo un síntoma; la manifestación de otro tipo de problemas, como trastornos de ansiedad o cuadros depresivos (Infobae, 2018). Siguiendo este razonamiento, resulta imprescindible generar espacios de reflexión en torno a las características 
que adopta la relación sujeto-objeto en el marco de las experiencias lúdicas inmersivas/ emersivas, debido a que existe la posibilidad de que "el videojuego no sea el objeto cultural problemático en sí mismo, sino el vehículo que la persona usa y que invisibiliza otra problemática" (Infobae, 2018).

\section{Propuestas y herramientas para abordar la problemática}

Existen numerosas organizaciones dedicadas a la clasificación de videojuegos de acuerdo a las mecánicas que emplean y los contenidos que proponen. Entre las más reconocidas se encuentra el Entertainment Software Rating Board (ESRB), un sistema estadounidense para clasificar el contenido de los videojuegos, asignándoles una categoría en función al tipo de contenido. La categorización ESRB se realiza de forma voluntaria e independiente. Asimismo, la organización difunde diversos lineamientos y principios de privacidad para la industria de videojuegos (ESRB, 2020).
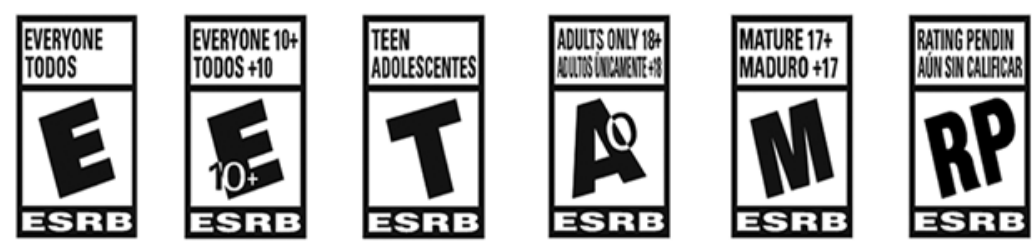

Figura 1. Clasificación ESRB. Fuente: https://www.esrb.org/ratings-guide/es/

La categorización ESRB se estructura de la siguiente manera: en una primera instancia, se clasifican los videojuegos según su contenido de violencia física, verbal o contenido sexual. La ESRB, a su vez, proporciona una innumerable cantidad de subcategorías para cada elemento. El principal objetivo de esta clasificación es orientar a padres y consumidores en la elección de los juegos que se ajusten a sus necesidades o las de su familia. En cuanto a la codificación, la ESRB utiliza símbolos simples y reconocibles (Ver Figura 1), letras alfabéticas que indican la etapa para la que es adecuado determinado juego/objeto. Actualmente, se basan en 6 categorías diferentes:

- Everyone: contenido apto para todas las edades. Estos juegos contienen escaso o nulo contenido violento; si lo tienen, es mínimo. Pueden contener, en algunos casos muy poco frecuentes, de lenguaje inadecuado. Esta clasificación se aplica, por ejemplo, a la mayoría de los juegos de deportes. 
- Everyone 10+: material adecuado para usuarios de 10 años o más. Los juegos incluidos en esta categoría generalmente presentan contenidos de violencia leve, sangre animada, algunos insultos regulares y/o en temas sugerentes.

- Teen: juegos que presentan contenido adecuado para adolescentes de 12 años o más. Los juegos comprendidos en esta categoría frecuentemente contienen sangre, humor cruel, temas sugerentes y/o violencia (moderada). Esta categoría se aplica, en la mayoría de los casos, a juegos de azar o apuestas.

- Mature 17+: esta clasificación comprende juegos o artículos con material adecuado para jugadores de 17 años o más. Los productos de esta categoría suelen contener escenas de violencia (a menudo intensa), sangre, mutilaciones, contenido sexual y/o insultos.

- Adults Only 18+: esta categoría delimita el contenido apto para adultos mayores de 18 años. Los títulos comprendidos bajo esta clasificación generalmente incluyen violencia intensa, sangre, escenas de desnudez, contenido sexual explícito, lenguaje extremadamente soez y, en algunos casos, juegos de apuestas con dinero real.

- Rating Pending: es la clasificación que reúne a todos los juegos enviados a la ESRB que se encuentran a la espera de su clasificación final (ESRB, 2020).

Otro reconocido sistema de clasificación de videojuegos y software de entretenimiento es el Pan European Game Information (PEGI), persigue un objetivo similar al de la ESRB: proporcionar orientación e información necesaria para elegir los productos que mejor se adecúen a la edad y necesidades de los usuarios. PEGI se organiza en torno a dos tipos de clasificación: una en función a la edad sugerida (Ver Figura 2) y otra de acuerdo al tipo de contenido. Esta última se divide en ocho categorías: lenguaje soez, discriminación, drogas, miedo, juego, contenido sexual, violencia, opciones de compra dentro del juego (PEGI, 2020).

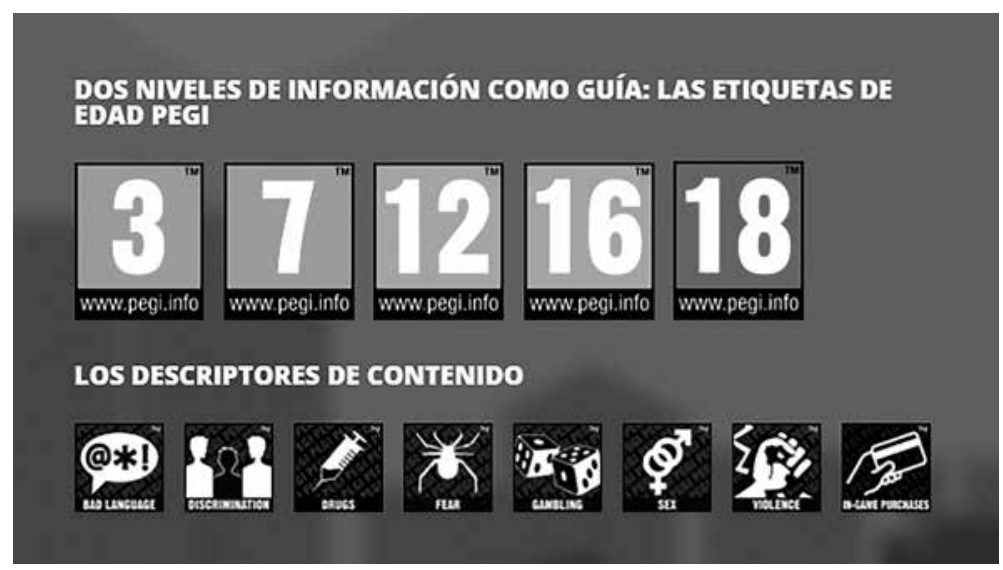

Figura 2. Clasificación PEGI. Fuente: https://pegi.info/es/ 
Por su parte, Google lanzó hace unos años un sitio llamado Digital Wellbeing, dedicado a la difusión de información sobre bienestar digital. En este portal las personas pueden aprender sobre diversos hábitos tecnológicos considerados correctos o deseables. Siguiendo esta línea, Apple presentó en el 2018 una serie de herramientas destinadas a concientizar sobre el uso excesivo de dispositivos tecnológicos, como medio para reducir y optimizar el tiempo empleado en los mismos (Infobae, 2018).

El nivel incipiente de toxicidad en los videojuegos es otra problemática que preocupa a muchos miembros de esa industria de experiencias lúdico inmersivas/emersivas. Allen Brack, presidente de Blizzard Entertainment, anunció que implementará en sus juegos una herramienta tendiente a reducir el comportamiento nocivo e indeseado en los juegos en línea, a partir del uso de machine learning (Schulkin, 2020). Al respecto, Amazon patentó este año un método que podría aislar a jugadores tóxicos dentro de los entornos virtuales de los juegos en red, mediante un sistema que puede identificar y clasificar a los tipos de jugadores de acuerdo a una serie de variables. Esta selección posibilitará la elección de jugadores conscientes para las plataformas de juegos electrónicos multijugador (Schulkin, 2020). "Los sistemas de emparejamiento o matchmaking en los juegos suelen enfocarse en agrupar a los jugadores de acuerdo al nivel de habilidad, pero según propone Amazon, hay otras consideraciones a tener en cuenta" (Schulkin, 2020). De lo anteriormente analizado resulta pertinente afirmar que la experiencia de juego puede variar, en gran medida, a partir de la interacción con otros usuarios. Si estos tienen un comportamiento considerado inapropiado para el individuo, la experiencia puede volverse sumamente negativa. Atendiendo a estas consideraciones,

Lo que haría esta tecnología es rastrear el comportamiento de usuarios que tienden a ser violentos en determinados juegos, insultando por ejemplo por voz o texto a otros usuarios... El sistema detectaría estos actos y pasaría a emparejar a estos usuarios solo con otros que actúen de la misma forma tóxica. La presentación permitiría a los jugadores seleccionar preferencias de conducta y lo que no consideran aceptable. Los jugadores se agruparían en función de estas preferencias (Schulkin, 2020).

En síntesis, parte fundamental de tener una experiencia de juego satisfactoria implica, para el usuario, sentirse bienvenido en el mundo virtual en el que está inmerso, esto significa que debe sentirse aceptado y respetado. Es por este motivo que la incorporación de dichas herramientas podrían significar un cambio radical en la experiencia de juego multiplataforma. 


\section{Visionar para el cambio}

\begin{abstract}
"La mayor parte de los problemas actuales, en particular los de carácter social, son de naturaleza compleja y requieren métodos y estrategias específicas para su abordaje; desde el Diseño de Transición se tomó el concepto de wicked problem proveniente de Rittel y Webber (1973), para referirse a este tipo de problema"
\end{abstract}

(D’Ortenzio, 2020/2021).

A partir de todo lo analizado hasta el momento, y utilizando las herramientas aportadas por el Diseño de Transición, se realizó un mapeo de conexión al wicked problem (Ver Figura 3) para determinar qué elementos configuran el entramado del problema elegido, así como los actores involucrados y el tipo de relaciones que entre ellos establecen. El objetivo de este ejercicio es identificar posibles puntos de apalancamiento (Meadows, 1999) para un cambio en el sistema observado. Para ello, en primera instancia, se circunscribe el problema a la siguiente variable: la toxicidad en los videojuegos inmersivos/emersivos. Siguiendo la técnica de mapeo esbozada por el Diseño de Transición, se analizó al wicked problem en función a cuatro ejes (Ver Figura 3):

- Infraestructura y tecnología, que abarca todos los recursos tecnológicos necesarios para el desarrollo de hardware y software relacionado a las experiencias inmersivas, así como sus potenciales aplicaciones y beneficios.

- Política y gobierno, dentro de lo que se incluyen las normas, iniciativas y campañas públicas destinadas a la concientización de los riesgos y difusión de información sobre las aplicaciones innovadoras de estas tecnologías que se traducen en impactos positivos en la salud y calidad de vida de los usuarios -a saber: aplicaciones en el ámbito de la educación, salud, integración-, como medio indispensable para comenzar a comprender el potencial que tienen estas experiencias inmersivas/emersivas cuando son empleadas más allá de sus fines lúdicos.

- Economía y finanzas, que comprende las inversiones públicas y privadas para investigación y desarrollo de nuevas tecnologías inmersivas/emersivas;

- Ambiente y ecosistemas, que hace referencia a los espacios físicos e intangibles que hacen posible la existencia de este tipo de experiencias inmersivas/emersivas. En el caso estudiado, se identifican en dos grupos: los espacios interiores (hogares y salas de juego diseñados para este tipo de experiencias) y los exteriores, al aire libre, que se intervienen a partir de tecnología portátil

- Relaciones sociales y principales actores intervinientes: esta variable involucra tanto a las empresas responsables como a los usuarios, a sus grupos de contención (familiares, amigos, grupos de pares), a los organismos colaborativos y autogestionados de regulación y, finalmente, a los desarrolladores visuales, e interactivos, de mecánicas y narrativas que dan forma a los universos virtuales y hacen posible la experiencia inmersiva y/o emersiva (Ver Figura 3). 
La cultura del diseño, "se ha vuelto un fenómeno global, que con el pasaje de la era del bienestar a la del capitalismo e hipercapitalismo ha gestado una nueva generación de consumidores de diseño" (Julier 2008, en Di Bella, 2020/2021, p. 97). En este marco, los diseñadores cumplen un rol preponderante en todo proceso creativo, en la medida que son los encargados de representar dichos universos virtuales, materializando lo intangible. Es decir, intervienen en el proceso dándole forma a la narrativa; la transponen al lenguaje visual para colocarla al alcance de los usuarios. Dicho en otras palabras: los diseñadores, junto con todo el equipo de desarrollo, materializan el universo icónico mediante la representación. Es por este motivo que su rol es fundamental a la hora de pensar formas innovadoras de interacción social. Aunando este razonamiento a los principios del Diseño de Transición,

Los diseñadores serán llamados a trabajar desde la prospectiva (Van der Heijden, 1998), es decir, implementando estrategias concretas, destinadas a la consecución de una serie de objetivos, que permitan mejorar la calidad de vida del grupo social, mediante una gestión más responsable de los recursos disponibles. El diseño, de esta manera, deberá visionar y proyectar escenarios futuros posibles y trabajar en pos de ello (D’Ortenzio, 2020, p. 142).

A partir del mapeo del wicked problem (Ver Figura 3) se identificaron los principales stakeholders, es decir, las partes involucradas en la problemática. A saber: los desarrolladores, las organizaciones destinadas a clasificar y catalogar los videojuegos, las empresas de hardware y tecnologías inmersivas y/o emersivas, el departamento de comunicación y márketing de las empresas productoras de videojuegos, la OMS, las organizaciones e instituciones que incorporan experiencias lúdicas inmersivas/emersivas para el tratamiento de patologías y la detección de trastornos, los diversos tipos de usuarios y, a su vez, sus grupos de contención y cuidado; los diseñadores gráficos y multimediales, los teóricos e investigadores de la imagen -que aportan información plausible de ser aplicada en el desarrollo de nuevos metaversos (universos virtuales)- y, finalmente, los creadores de las narrativas -historia, metas y objetivos- que configuran el universo virtual y ponen al juego en acción. 


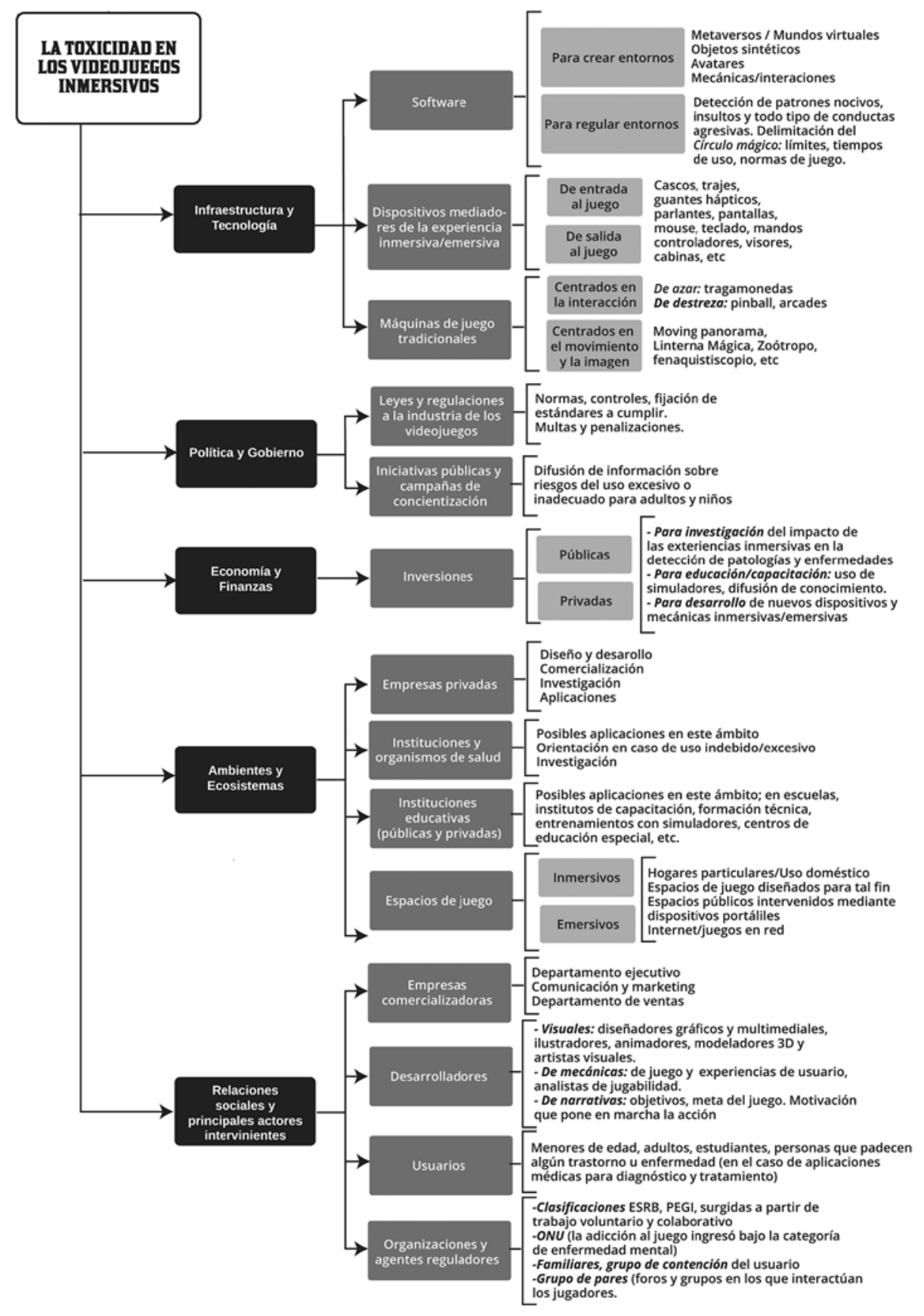

Figura 3. Mapeo de conexión al Wicked Problem. Fuente: elaboración propia. 
Atendiendo a estas consideraciones y tomando como punto de referencia los Objetivos del Desarrollo Sostenible ODS establecidos por el Programa de las Naciones Unidas para el Desarrollo (Ver Figura 4), los cuales "conllevan un espíritu de colaboración y pragmatismo para elegir las mejores opciones con el fin de mejorar la vida, de manera sostenible, para las generaciones futuras." PNUD (2020), este trabajo se propone impactar sobre las siguientes esferas:

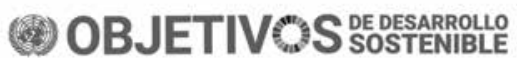
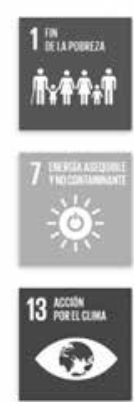
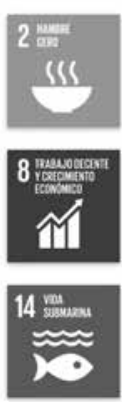
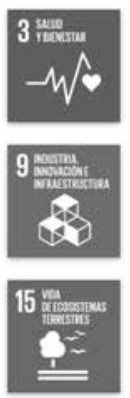
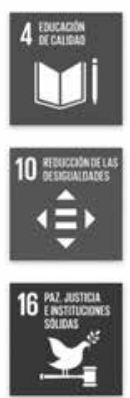
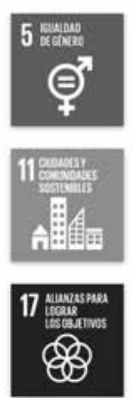
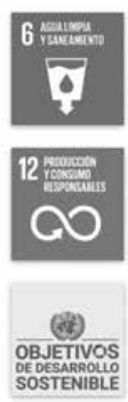

Figura 4. Objetivos para el desarrollo sostenible (ODS). Fuente: https://www.undp.org/ content/undp/es/home/sustainable-development-goals.html

- Salud y bienestar (Objetivo 3): los medios interactivos, lejos de cumplir una función meramente lúdica, pueden utilizarse como medio para fortalecer vínculos entre los miembros de una comunidad y así consolidar redes de apoyo y contención para aquellos usuarios más vulnerables. Un claro ejemplo de la influencia de los entornos digitales en la vida de las personas puede encontrarse en las acciones llevadas a cabo por la Asociación de Hombres y Mujeres Nuevos de Panamá (AHMNP) durante el aislamiento a causa de la pandemia provocada por el COVID-19: de acuerdo a un artículo publicado por ONU Desarrollo (2020) las redes sociales y ciertas aplicaciones digitales han proporcionado un espacio clave de vinculación entre los promotores de salud pertenecientes a la AHMNP y sectores afectados o expuestos al virus del VIH en Panamá. Estos voluntarios, al verse imposibilitados de salir a la calle por la pandemia, adoptaron un enfoque digital para acercarse a la gente afectada. En este caso, "El poder de las redes sociales, cuyos usuarios ascienden a 2,4 millones en Panamá, es decir, un poco más de la mitad de la población, ra- 
dica en el hecho que los promotores de salud comunitaria pueden interactuar de manera segura con la gente desde sus casas" (ONU Desarrollo, 2020).

- Igualdad y género (objetivo 5): repensar las narrativas de los juegos implica analizar y desarmar las formas más estereotipadas de representación de lo femenino dentro de los universos virtuales, habilitando nuevas instancias de participación y experimentación de los metaversos y avatares. "Se ha demostrado una y otra vez que empoderar a las mujeres y niñas tiene un efecto multiplicador y ayuda a promover el crecimiento económico y el desarrollo a nivel mundial" (PNUD, 2020). Por otra parte, los juegos interactivos constituyen espacios de interacción e intercambio entre diversos usuarios, permitiéndole a cada uno de ellos elegir una apariencia y un conjunto de características con las cuales identificarse lo que, como se ha mencionado anteriormente, produce la estimulación de procesos empáticos, fenómeno que puede traducirse, bajo el marco adecuado, en una actitud más respetuosa e inclusiva hacia otros usuarios.

- Producción y consumo responsable (Objetivo 12): en relación al impacto que tiene la industria de videojuegos en el medioambiente. Al respecto, la ONU establece que "Para lograr crecimiento económico y desarrollo sostenible, es urgente reducir la huella ecológica mediante un cambio en los métodos de producción y consumo de bienes y recursos" (PNUD, 2020). Para ello, resulta imprescindible comprender el grado de impacto que tienen los hábitos de consumo vinculados a las experiencias lúdicas inmersivas/emersivas, no sólo al nivel de desechos físicos producidos por consumo excesivo, y consecuente descarte, de dispositivos sino en cuanto al consumo energético requerido para llevar a cabo estas experiencias virtuales.

- Paz, justicia e instituciones sólidas (objetivo 16): este punto está vinculado a "promover sociedades justas, pacíficas e inclusivas" (PNUD, 2020). Como se ha mencionado, la toxicidad en los videojuegos es una preocupación en aumento para las empresas pertenecientes a la industria de experiencias digitales inmersivas, hecho que ha motivado al desarrollo de software y aplicaciones destinadas a detectar comportamientos nocivos y aislar a jugadores violentos. Esta toma de medidas destinadas a asegurar entornos de juego más saludables e inclusivos se relaciona a este objetivo del PNUD, el cual promueve todo tipo de acciones destinadas a reducir cualquier forma de violencia.

Atendiendo a estas consideraciones, la visión de futuro propuesta en este trabajo deberá contemplar la labor colaborativa e interdisciplinar para el desarrollo de aplicaciones innovadoras y nuevos modos de interacción humano-realidad, en miras a reducir los impactos negativos de la utilización de la tecnología de forma irresponsable. A su vez, esta visión debe estar orientada hacia el aumento de los impactos positivos derivados del uso de las tecnologías y experiencias inmersivas/emersivas. Fenómeno que se traduciría, a mediano plazo, en una notable mejora de la calidad de vida de los individuos, a través de la estimulación de procesos empáticos y la correcta regulación/categorización de los universos virtuales. 


\section{Conclusiones}

Para concluir, se enumeran una serie de preguntas enunciadas a partir del análisis realizado en torno a las experiencias inmersivas/emersivas y su impacto en el cuerpo social, así como algunas ideas y esbozos de respuestas:

- Será necesario un equipo interdisciplinario que se ocupe de indagar formas innovadoras de emersión e inmersión, a partir del análisis de los impactos de la relación hombre-máquina, realidad/virtualidad? A partir de lo analizado anteriormente se concluye que la visión propuesta requerirá un cambio de paradigma en cuanto a la forma de entender y definir el rol y el alcance de las experiencias lúdicas inmersivas/emersivas, entendiendo la potencialidad de las mismas, tanto para impactos positivos como negativos; sociales y ambientales. A su vez, una comprensión más acabada de esto implica considerar a todos agentes involucrados para que estas experiencias inmersivas/emersivas tengan lugar.

Por otra parte, explorar el desvanecimiento de las fronteras entre el mundo del juego y la realidad ordinaria es un paso indispensable para comprender las complejidades que rodean a la relación del sujeto con las experiencias inmersivas, así como su efecto en la conducta y la vida de las personas. Siguiendo esta línea, el presente trabajo indaga sobre el origen del vínculo de los individuos con las experiencias lúdicas tradicionales, en primera instancia, y las máquinas de juego, en segundo lugar. A partir de este enfoque arqueológico del juego, se arribó a la conclusión de que este fue, a principios del S.XX, una clara "manifestación de la relación entre ser humano y máquina” (Huhtamo 2007, p. 2) que, con el tiempo, ha migrado hacia el concepto de experiencia.

Este movimiento, como se ha mencionado, respondió a la necesidad de desligar al juego de su valoración históricamente negativa. A saber: la noción de juego como algo serio sigue siendo controversial aún hoy; la actividad lúdica, cualquiera sea, es víctima, paradójicamente, de los argumentos esgrimidos por la propia industria para popularizar el uso de las máquinas de juego en la modernidad. Comprender el contexto a partir del cual se construye el imaginario que rodea al acto de jugar, lejos de ser algo anecdótico, es pieza fundamental para comprender los universos de sentido que entran en juego a la hora de experimentar una experiencia lúdica inmersiva.

- ¿Cómo es la relación sujeto-avatar? ¿Cómo podría ser? De lo relevado en el marco de este trabajo, se concluye que el ser humano no sólo tiene un impulso hacia la inmersión, evidenciado en el gran número de producciones artísticas llevadas a cabo desde la antigüedad sino que, a su vez, presenta un deseo casi instintivo, primario, de reconocimiento -de los otros y de sí mismo-. Allí radica el poder de la imagen: los modelos de representación, por rudimentarios que sean, han permitido a los hombres dejar un registro de su existencia a lo largo de la historia. Siguiendo esta línea, la imagen es, a la vez, espejo y ente autónomo: una vez realizada la representación, la copia, esta pone en marcha una serie de significaciones que escapan al control del sujeto real. Por otra parte, como se mencionó al principio de este trabajo, el juego requiere una suspensión de la realidad y un círculo mágico donde todo sea posible. Lo que media la interacción con ese universo ficcional es la representación icónica, los elementos sintéticos que configuran el espacio inmaterial. Es 
por este carácter legitimador que la imagen es un recurso tan potente: difumina los límites de lo real y lo virtual, fundiendo ambas nociones en una sola cosa.

En cuanto a la relación sujeto-representación icónica, resulta pertinente resaltar el hecho analizado de que la avatarización de la mirada, tan característica de las experiencias inmersivas, contribuye a la estimulación de procesos empáticos entre los usuarios. Expresado de otra manera, la posibilidad de moldear el propio sustituto virtual, adoptando cualquier característica, como se ha mencionado anteriormente, permite al usuario percibirse de forma distinta y experimentar la mirada ajena.

- ¿Nos dirigimos hacia una sociedad de espejismos digitales? ¿Cuáles son los límites? ¿Quién los va a regular? Si bien la atracción del ser humano por las experiencias lúdicas se remonta a los comienzos de la humanidad, en la actualidad se observa un auge de las experiencias emersivas/inmersivas. Este tipo de videojuegos fusionan los principales atractivos: poseen una narrativa, facilitan la interacción con otros usuarios, independientemente de su localización geográfica -si el juego posee una plataforma multijugador-, habilitan la posibilidad de vivenciar espacios virtuales inimaginables y, finalmente, el tema eje de este trabajo: permiten habitar un cuerpo que el propio usuario ha moldeado, una identidad que no conoce límites y puede modificarse infinitamente. Ante este amplio espectro de posibilidades, los jugadores se encuentran seducidos y atrapados dentro de estos universos virtuales, al punto de que, en muchos casos, estos han redefinido la forma de percibirse a sí mismo, consumir productos culturales y hasta vincularse con otros (Pinotti, 2020). Actualmente, la tecnología media casi todas las actividades humanas. Aquí radica el peligro de estos universos intangibles y es, en consecuencia, el punto donde la reflexión en torno a la relación sujeto-juego adquiere mayor relevancia.

A partir de lo investigado para este trabajo, se concluye que son necesarios ciertos límites y regulaciones tendientes a reducir los impactos negativos de experiencias inmersivas y emersivas. Las regulaciones vigentes, tal como se ha mencionado anteriormente, se sustentan, en gran medida, en el trabajo colectivo y voluntario de los miembros de la comunidad de videojuegos. Por otra parte, el hecho observado de que algunas empresas reconocidas hayan comenzado a implementar nuevas técnicas y herramientas destinadas a reducir la toxicidad en los videojuegos o a concientizar sobre el uso excesivo de los dispositivos electrónicos, tal como se ha mencionado anteriormente, constituye un paso fundamental hacia la concreción de experiencias lúdicas emersivas/inmersivas más seguras e inclusivas.

\section{Lista de referencias bibliográficas}

Belting, H. (2007). Antropología de la imagen. Buenos Aires: Katz Editores.

Di Bella, D. V. (2018). Informe de Impacto de la Experiencia Diseño en Perspectiva. En Diseño en Perspectiva - Diseño para la transición en Cuaderno del Centro de Estudios de Diseño y Comunicación $N^{\circ}$ 80, pp. 173-239. Buenos Aires: Universidad de Palermo.

Digital Wellbeing (2020). Find a balance with technology that feels right for you. Disponible en https://wellbeing.google Recuperado el 8/11/2020 
D’Ortenzio V. M. (2020). Hiperconectados. La señalética y su impacto en los consensos sociales. En Visiones del Diseño III: Problematizar el Diseño para Comprender su Complejidad en Cuaderno del Centro de Estudios de Diseño y Comunicación $\mathrm{N}^{\circ}$ 105, pp. 125-146. Buenos Aires: Universidad de Palermo

ESRB (2020). Entertainment Software Rating Board. Disponible en https://www.esrb.org Recuperado el 25/11/2020.

Freud, A. (1966). The Ego and the Mechanisms of Defense. Nueva York: International Universities Press.

Gallastegui, S. (2018). Inmersión y emersión en los juegos digitales. Un modelo de análisis, en Icono $N^{\circ} 16$ (2) Pp. 51-73. Disponible en https://icono14.net/ojs/ index.php/icono14 / article/view/1155 Recuperado el 28/10/2020

Huhtamo, E. [ArtCenter College of Design]. (2017, Septiembre 8). Simposio Free Radicals: Evolving Perspectives on the Convergence of Art \& Science - Ponencia: Media Manias [Archivo de video]. Recuperado de https://vimeo.com/237119821

Huhtamo, E. (2007). Máquinas de diversión, máquinas de problemas en Artnodes: revista de arte, ciencia y tecnología No7, Pp. 46-64. Disponible en: http://artnodes.uoc.edu. Recuperado el 10/12/2020.

Huizinga, J. (2007). Homo Ludens. Madrid: Alianza.

Infobae (2018). La OMS actualizó su clasificación internacional de enfermedades e incluyó la adicción a los videojuegos Disponible en https://www.infobae.com/salud/2018/06/19/ la-oms-actualizo-su-clasificacion-internacional-de-enfermedades-e-incluyo-la-adiccion -a-los-videojuegos Recuperado el 8/11/2020

Irwin, T. (2019). The Emerging Transition Design Approach. En Diseño en Perspectiva-Diseño para la Transición en Cuaderno del Centro de Estudios en Diseño y Comunicación $\mathrm{N}^{\circ} 73$. Buenos Aires: Universidad de Palermo.

Kossoff, G. (2011). Holism and the Reconstitution of Everyday Life: A Framework for Transition to a Sustainable Society Ph.D. thesis, University of Dundee.

La Nación (2018). La adicción a los videojuegos Disponible en https://www.lanacion.com. ar/opinion/la-adiccion-a-videojuegos-nid2159198 Recuperado el 6/11/2020

ONU Desarrollo (2020). La vida en tiempos de confinamiento. Disponible en https:// pnud.medium.com/la-vida-en-tiempos-de-confinamiento-41aa0141620f Recupeado el 18/11/20.

Meadows, D. (1999). Leverage Points: Places to intervene in a system. The Sustainability Institute. Disponible en: http://donellameadows.org/wp-content/userfiles/Leverage_Points. pdf Recuperado el 25/10/2019.

Montola, M. (2005). Exploring the edge of the magic circle: defining pervasive games. Vol. 1966, Pp. 16-19. Disponible en DAC http://remotedevice.Net/main/cmap/explor ingtheedge. Pdf Recuperado el: 20/11/2020.

OMS (2020) ICD-11 for Mortality and Morbidity Statistics Disponible en https://icd.who. int/browse11/l-m/en\#/http://id.who.int/icd/entity/1448597234 Recuperado el 5/11/2020

Pinotti, A. (2020). Procuradores del sí mismo: del avatar a la avataricación. Disponible en: https://ficciondelarazon.org/2020/02/17/andrea-pinotti- procuradores-del-si-mismodel-avatar-a-la-avatarizacion Recuperado el 05/10/2020 
PEGI (2020). Pan European Game Information. Disponible en https://pegi.info Recuperado el $25 / 11 / 2020$

PNUD (2020). Objetivos del Desarrollo Sostenible (ODS) Programa de las Naciones Unidas para el Desarrollo. Disponible en: https://www.undp.org/content/undp/es/home/sustai nable-development-goals-old.html Recuperado el 05/10/2020

Schulkin, J. (2020). Se patentó un nuevo proyecto para reducir la toxicidad en las comunidades de videojuegos. Disponible en https://www.infobae.com/gaming/2020/11/13/se-patento -un-nuevo-proyecto-para-reducir-la-toxicidad-en-las-comunidades-de-videojuegos Recuperado el 10/11/2020.

Tillería Aqueveque, L. (2019). Baudrillard. Filosofía de la seducción en Revista Humanidades $\mathrm{N}^{\circ} 9$ (2), Pp, 1-21. Disponible en https://doi.org/10.15517/h.v9i2.3751 Recuperado el $15 / 11 / 2020$.

Vinlove, A. (2020). Cuerpos que importan. Reflexionando sobre el estado actual de la industria del denim y las problemáticas que contiene. En Visiones del Diseño III: Problematizar el Diseño para Comprender su Complejidad en Cuaderno del Centro de Estudios de Diseño y Comunicación N ${ }^{\circ} 105$, pp. 147-163. Buenos Aires: Universidad de Palermo.

\section{Bibliografía}

Belting, H. (2007). Antropología de la imagen. Buenos Aires: Katz Editores.

Cuaderno del Centro de Estudios en Diseño y Comunicación No105. (2020) Visiones del Diseño III: Problematizar el Diseño para Comprender su Complejidad. Coordinación Daniela V. Di Bella (UP) y Terry Irwin (CMU). Facultad de Diseño y Comunicación Año XXIII, Buenos Aires, Argentina. ISSN: 1668-0227 (Publicación: 2020/2021).

Cuaderno del Centro de Estudios en Diseño y Comunicación No87. (2019) Visiones del Diseño II: Diseñadores Eco-Sociales. Coordinación Daniela V. Di Bella (UP) y Terry Irwin (CMU). Facultad de Diseño y Comunicación Año XXI, Buenos Aires, Argentina. ISSN: 1668-0227 (Publicación: 2019/2020).

Cuaderno del Centro de Estudios en Diseño y Comunicación No80. (2018) Diseño en Perspectiva - Diseño para la transición. Segunda Sección. Coordinación Daniela V. Di Bella (UP) y Terry Irwin (CMU). Facultad de Diseño y Comunicación Año XXI, Buenos Aires, Argentina. ISSN: 1668-0227 (Publicación: 2020).

Cuaderno del Centro de Estudios en Diseño y Comunicación No73. (2017) Diseño en Perspectiva - Diseño para la transición. Primera Sección. Coordinación Terry Irwin (CMU) y Daniela V. Di Bella (UP). Facultad de Diseño y Comunicación Año XIX, Buenos Aires, Argentina. ISSN: 1668-0227 (Publicación: 2019).

Di Bella, D. V. (2018). Informe de Impacto de la Experiencia Diseño en Perspectiva. En Diseño en Perspectiva - Diseño para la transición en Cuaderno del Centro de Estudios de Diseño y Comunicación $N^{\circ}$ 80, pp. 173-239. Buenos Aires: Universidad de Palermo.

Digital Wellbeing (2020). Find a balance with technology that feels right for you. Disponible en https://wellbeing.google Recuperado el 8/11/2020. 
D’Ortenzio V. M. (2020). Hiperconectados. La señalética y su impacto en los consensos sociales. En Visiones del Diseño III: Problematizar el Diseño para Comprender su Complejidad en Cuaderno del Centro de Estudios de Diseño y Comunicación N ${ }^{\circ} 105$, pp. 125-146. Buenos Aires: Universidad de Palermo.

ESRB (2020). Entertainment Software Rating Board. Disponible en https://www.esrb.org Recuperado el 25/11/2020

Frascara, J. (2006) La desmaterialización del diseño: Un nuevo perfil del diseño de comunicación. Actas de Diseño No1. Buenos Aires: Imprenta Kurz.

Freud, A. (1966). The Ego and the Mechanisms of Defense. Nueva York: International Universities Press.

Gallastegui, S. (2018). Inmersión y emersión en los juegos digitales. Un modelo de análisis, en Icono $N^{\circ} 16$ (2) Pp. 51-73 Disponible en https://icono14.net/ojs/ index.php/icono14/ article/view/1155 Recuperado el 28/10/2020.

Huhtamo, E. [ArtCenter College of Design]. (2017, Septiembre 8). Simposio Free Radicals: Evolving Perspectives on the Convergence of Art \& Science - Ponencia: Media Manias [Archivo de video]. Recuperado de https://vimeo.com/237119821.

Huhtamo, E. (2007). Máquinas de diversión, máquinas de problemas en Artnodes: revista de arte, ciencia y tecnología No7, Pp. 46-64. Disponible en: http://artnodes.uoc.edu. Recuperado el 10/12/2020

Huizinga, J (2007). Homo Ludens. Madrid: Alianza.

Infobae (2018). La OMS actualizó su clasificación internacional de enfermedades e incluyó la adicción a los videojuegos Disponible en https://www.infobae.com/salud/2018/06/19/ la-oms-actualizo-su-clasificacion-internacional-de-enfermedades-e-incluyo-la-adiccion -a-los-videojuegos Recuperado el 8/11/2020

Irwin, T. (2019). The Emerging Transition Design Approach. En Diseño en Perspectiva-Diseño para la Transición en Cuaderno del Centro de Estudios en Diseño y Comunicación $N^{\circ} 73$. Buenos Aires: Universidad de Palermo.

Irwin, T.; Tonkinwise, C. \& Kossoff, G. (2015). Transition Design: An educational framework for advancing the study and design of sustainable transitions. Paper presented the Sustainability Transitions Research Network Conference, Brighton, United Kingdom.

La Nación (2018). La adicción a los videojuegos Disponible en https://www.lanacion.com. ar/opinion/la-adiccion-a-videojuegos-nid2159198 Recuperado el 6/11/2020

Meadows, D. (1999). Leverage Points: Places to intervene in a system. The Sustainability Institute. Disponible en: http://donellameadows.org/wp-content/userfiles/Leverage_Points. pdf Recuperado el 25/10/2019.

Montola, M. (2005) Exploring the edge of the magic circle: defining pervasive games. Vol. 1966, Pp. 16-19. Disponible en DAC http://remotedevice.Net/main/cmap/explor ingtheedge. Pdf Recuperado el: 20/11/2020.

OMS (2020) ICD-11 for Mortality and Morbidity Statistics Disponible en https://icd.who. int/browse11/l-m/en\#/http://id.who.int/icd/entity/1448597234 Recuperado el 5/11/2020

ONU Desarrollo (2020) La vida en tiempos de confinamiento. Disponible en https://pnud.me dium.com/la-vida-en-tiempos-de-confinamiento-4laa0141620f Recupeado el 18/11/20 
Pinotti, A. (2020). Procuradores del sí mismo: del avatar a la avataricación. Disponible en: https://ficciondelarazon.org/2020/02/17/andrea-pinotti-procuradores-del-si-mismodel-avatar-a-la-avatarizacion Recuperado el 05/10/2020

PEGI (2020). Pan European Game Information. Disponible en https://pegi.info Recuperado el 25/11/2020.

PNUD (2020). Objetivos del Desarrollo Sostenible (ODS) Programa de las Naciones Unidas para el Desarrollo. Disponible en: https://www.undp.org/content/undp/es/home/sustai nable-development-goals-old.html Recuperado el 05/10/2020.

Schulkin, J. (2020). Se patentó un nuevo proyecto para reducir la toxicidad en las comunidades de videojuegos. Disponible en https://www.infobae.com/gaming/2020/11/13/se-patento -un-nuevo-proyecto-para-reducir-la-toxicidad-en-las-comunidades-de-videojuegos Recuperado el 10/11/2020.

Thackara, J. (2013). Diseñando para un mundo complejo. Ciudad de México: Editorial Designio.

Tillería Aqueveque, L. (2019). Baudrillard. Filosofía de la seducción en Revista Humanidades N9 (2), Pp, 1-21. Disponible en https://doi.org/10.15517/h.v9i2.3751 Recuperado el $15 / 11 / 2020$.

Vinlove, A. (2020). Cuerpos que importan. Reflexionando sobre el estado actual de la industria del denim y las problemáticas que contiene En Visiones del Diseño III: Problematizar el Diseño para Comprender su Complejidad en Cuaderno del Centro de Estudios de Diseño y Comunicación Nº 105, pp. 147-163. Buenos Aires: Universidad de Palermo.

\begin{abstract}
In a world immersed in virtuality, ecstatic with images and visual stimuli, both the perception of otherness and one's own identity tend to undergo alterations to adapt to the environment. The emergence of virtual meeting spaces, such as blogs, forums and social networks, consolidated the massification of an extremely seductive and hitherto unthinkable figure: the digital avatar; the possibility of adopting, personalizing, or shaping one's own virtual identity and, with it, new ways of understanding links. Faced with these two realities (virtual and immaterial) the subject would seem to find himself split, in permanent conflict between his projected and self-perceived image. The question that then arises and sets this article in motion is the following: to what extent does the iconic representation, the digital surrogate, determine the way in which individuals perceive themselves and connect with others? Finally, based on the tools provided by Transitional Design, appealing to notions of image archeology and philosophy as theoretical support and framework, this work aims to investigate the level of impact that immersive and emersive experiences have in the identity construction and linking of individuals, as a starting point to think, from the design, more friendly virtual environments, reducing negative impacts and enhancing their positive contributions.
\end{abstract}

Keywords: Game - Image - Identity - Immersion - Design - Interaction- Inclusion - Emersion - User experience - Society - Virtuality. 
Resumo: Em um mundo imerso na virtualidade, extasiado com imagens e estímulos visuais, tanto a percepção da alteridade quanto a própria identidade tendem a sofrer alterações para se adaptar ao ambiente. O surgimento de espaços virtuais de encontro, como blogs, fóruns e redes sociais, consolidou a massificação de uma figura extremamente sedutora e até então impensável: o avatar digital; a possibilidade de adotar, personalizar ou conformar a própria identidade virtual e, com ela, novas formas de compreensão dos vínculos. Diante dessas duas realidades (virtual e imaterial) o sujeito parece se encontrar dividido, em permanente conflito entre sua imagem projetada e a autopercebida. A questão que então surge e põe em movimento este artigo é a seguinte: em que medida a representação icônica, o substituto digital, determina a forma como os indivíduos se percebem e se conectam com os outros? Por fim, com base nas ferramentas fornecidas pelo Transitional Design, recorrendo a noções de arqueologia da imagem e filosofia como suporte teórico e enquadramento, este trabalho visa investigar o nível de impacto que as experiências imersivas e emersivas têm. Na construção da identidade e vinculação dos indivíduos, como ponto de partida pensar, desde o design, ambientes virtuais mais amigáveis, reduzindo impactos negativos e potencializando suas contribuições positivas.

Palavras-chave: Jogo - Imagem - Identidade - Imersão - Design - Interação - Inclusão Emersão - Experiência do usuário - Sociedade - Virtualidade. 